\title{
Studies of Rearrangement Reactions of Protonated and Lithium Cationized 2-Pyrimidinyloxy-N-Arylbenzylamine Derivatives by MALDI-FT-ICR Mass Spectrometry
}

\author{
Hao-Yang Wang and Yin-Long Guo
}

Shanghai Mass Spectrometry Center, Shanghai Institute of Organic Chemistry, Chinese Academy of Sciences, Shanghai, People's Republic of China

\section{Long $\mathrm{Lu}$}

Key Laboratory of Organofluorine Chemistry, Shanghai Institute of Organic Chemistry, Chinese Academy of Sciences, Shanghai, People's Republic of China

The rearrangement reactions of protonated and lithium-cationized 2-pyrimidinyloxy- $\mathrm{N}$ arylbenzylamine derivatives were studied by Fourier transform ion cyclotron resonance mass spectrometry (FT-ICR MS) and infrared multiphoton dissociation mass spectrometry (IRMPD). Our results show that three kinds of rearrangement reactions occur in IRMPD processes. First, nearly all protonated 2-pyrimidinyloxy- $\mathrm{N}$-arylbenzylamine derivatives undergo Pathway $\mathbf{A}$ to form the $K$ ion series. It is proposed that this rearrangement (migration of a substituted benzyl group) proceeds by way of a gas-phase intramolecular $\mathrm{S}_{\mathrm{N}} 2$ reaction. Second, a gas phase intramolecular $\mathrm{S}_{\mathrm{N}} \mathrm{Ar}$ type rearrangement mechanism is proposed to explain the formation of the $F$ ion series from protonated and lithium-cationized 5 (or 6). This skeletal rearrangement reaction competes with the $S_{N} 2$ reaction of the Pathway $A$, which produces the $K$ ion series, in IRMPD of protonated 5 and $\mathbf{6}$. Third, the formation pathway of the $W$ ion series is explained by a gas phase Cope type rearrangement mechanism. (J Am Soc Mass Spectrom 2004, 15, 1820-1832) (c) 2004 American Society for Mass Spectrometry

$\mathrm{T}$ The development of environmentally-benign herbicides has become a major focus in herbicide research. 2-Pyrimidinyloxy- $\mathrm{N}$-arylbenzylamine derivatives with favorable properties, such as a low dose rate of application and a high degree of (bio)degradation, were developed by the Shanghai Institute of Organic Chemistry together with Zhejiang Chemical and Industrial Technology Ltd. This novel, efficient herbicide has been applied in rape fields successfully. For simplicity in this discussion, the eight compounds studied here are each assigned a number (1 to 8$)$, as shown in the Scheme $\mathbf{1}$.

Previous EI mass spectrometry studies have demonstrated that these compounds have some unique gasphase chemistry [1]. No systematic study, however, has been reported for MS/MS data of the protonated and lithium-cationized ions of these compounds. A thorough understanding of the MS/MS and $\mathrm{MS}^{\mathrm{n}}$ data of these herbicides is necessary for further development of these compounds [2]. Protonated ions often undergo gas-phase

Published online November 2, 2004

Address reprint requests to Dr. Y.-L. Guo, Shanghai Mass Spectrometry Center, Shanghai Institute of Organic Chemistry, Chinese Academy of Sciences, Shanghai 200032, P. R. China. E-mail: ylguo@mail.sioc.ac.cn rearrangement [3-13]. The gas-phase rearrangement reactions of peptides and modified peptides have been investigated in many previous reports [3-9]. Gas-phase intramolecular nucleophilic displacement [3-9] and ionneutral complex mechanisms [13] are used to interpret the gas-phase rearrangement processes. For example, in the fragmentation reaction of protonated cysteine, the thiolneighboring group facilitates loss of $\mathrm{NH}_{3}$ [3]. More recently, the gas-phase rearrangement of farnesyl transferase inhibitor has been reported; this process involves a gas-phase intramolecular $S_{N} 2$ reaction [10].

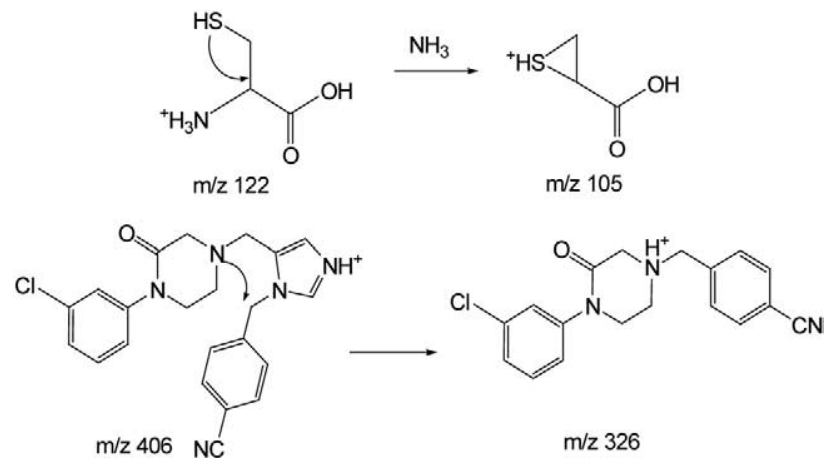


<smiles>COc1cc(OC)nc(Oc2ccccc2CNc2ccc(C(=O)OC(C)C)cc2)n1</smiles>

1 M.W. 423<smiles>COc1cc(OC)nc(Oc2ccccc2CNc2ccc(Br)cn2)n1</smiles>

5 M.W. 416<smiles>COc1cc(OC)nc(Oc2cccc(Cl)c2CNc2ccc(C(=O)OC(C)C)cc2)n1</smiles>

2 M.W. 457<smiles>COc1cc(OC)nc(Oc2cccc(Cl)c2CNc2ccc(Br)cn2)n1</smiles><smiles>COc1cc(OC)nc(Oc2ccccc2CNc2ccc(C(=O)N3CCCCC3)cc2)n1</smiles>

3

M.W. 448<smiles>COc1cc(OC)nc(Oc2ccccc2CNc2ccccc2Br)n1</smiles>

$7 \quad$ M.W. 416<smiles>CCN(CC)C(=O)c1ccc(NCc2c(Cl)cccc2Oc2nc(OC)cc(OC)n2)cc1</smiles>

M.W. 470

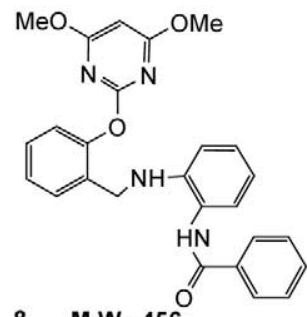

Scheme 1. Chemical structures of 2-Pyrimidinyloxy- $N$-arylbenzylamine derivatives (1 to 8 , molecular weight in $\mathrm{Da}$.).

IRMPD has been shown to be a viable alternative to CAD for probing molecular structures [4-19]. IRMPD does not appreciably alter the kinetic energy or stable orbits of the trapped ions.

Analysis of the IRMPD data reveals interesting and remarkable gas-phase reactions of these compounds, which include gas-phase intramolecular $\mathrm{S}_{\mathrm{N}} 2$ reactions, a $\mathrm{S}_{\mathrm{N}} \mathrm{Ar}$ type skeletal rearrangement reaction, and a gas-phase Cope type rearrangement reaction. Herein, the fragmentation patterns of the protonated 2-pyrimidinyloxy- $N$-arylbenzylamine derivatives are generalized into three main modes (Pathways $\mathbf{A}, \mathbf{B}$, and $\mathbf{C}$ ) and the structures of three kinds of ions $(K, P$, and $F$, respectively) are also proposed.

Of note is the finding that the ESI-in-source CAD spectrum of protonated 5 (or 6 ) contains only the ion at
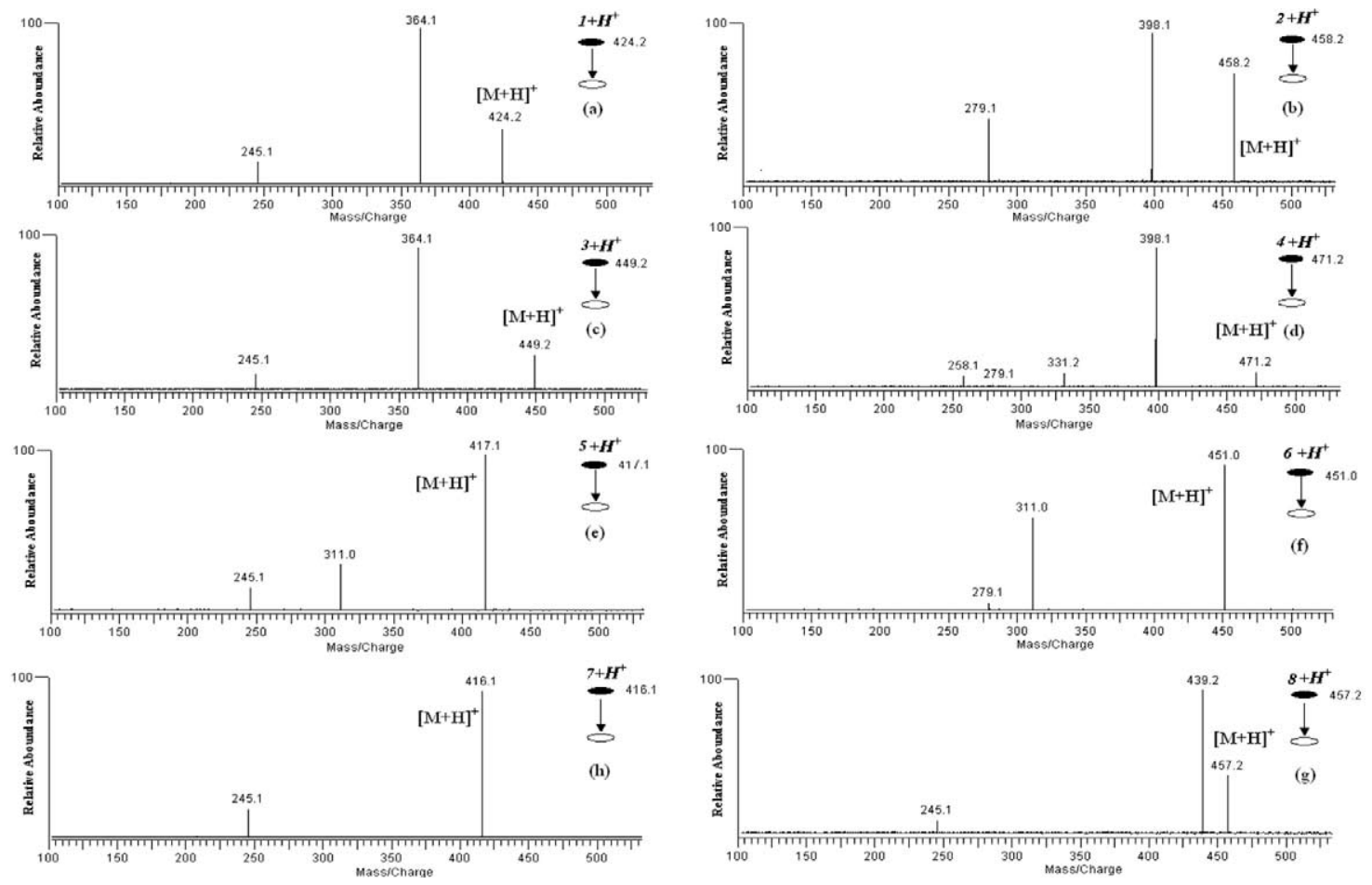

Figure 1. The IRMPD spectra of protonated 1 to 8: (a) Protonated 2 at $\mathrm{m} / \mathrm{z} 424$; (b) protonated 2 at $\mathrm{m} / \mathrm{z}$ 458; (c) protonated 3 at $m / z$ 449; (d) protonated 4 at $\mathrm{m} / \mathrm{z}$ 471; (e) protonated 5 at $\mathrm{m} / \mathrm{z}$ 417; (f) IRMPD of protonated 6 at $\mathrm{m} / \mathrm{z} 451 ; \mathbf{g})$ protonated 7 at $\mathrm{m} / \mathrm{z}$ 416; (h) protonated 8 at $\mathrm{m} / \mathrm{z} 457$. 


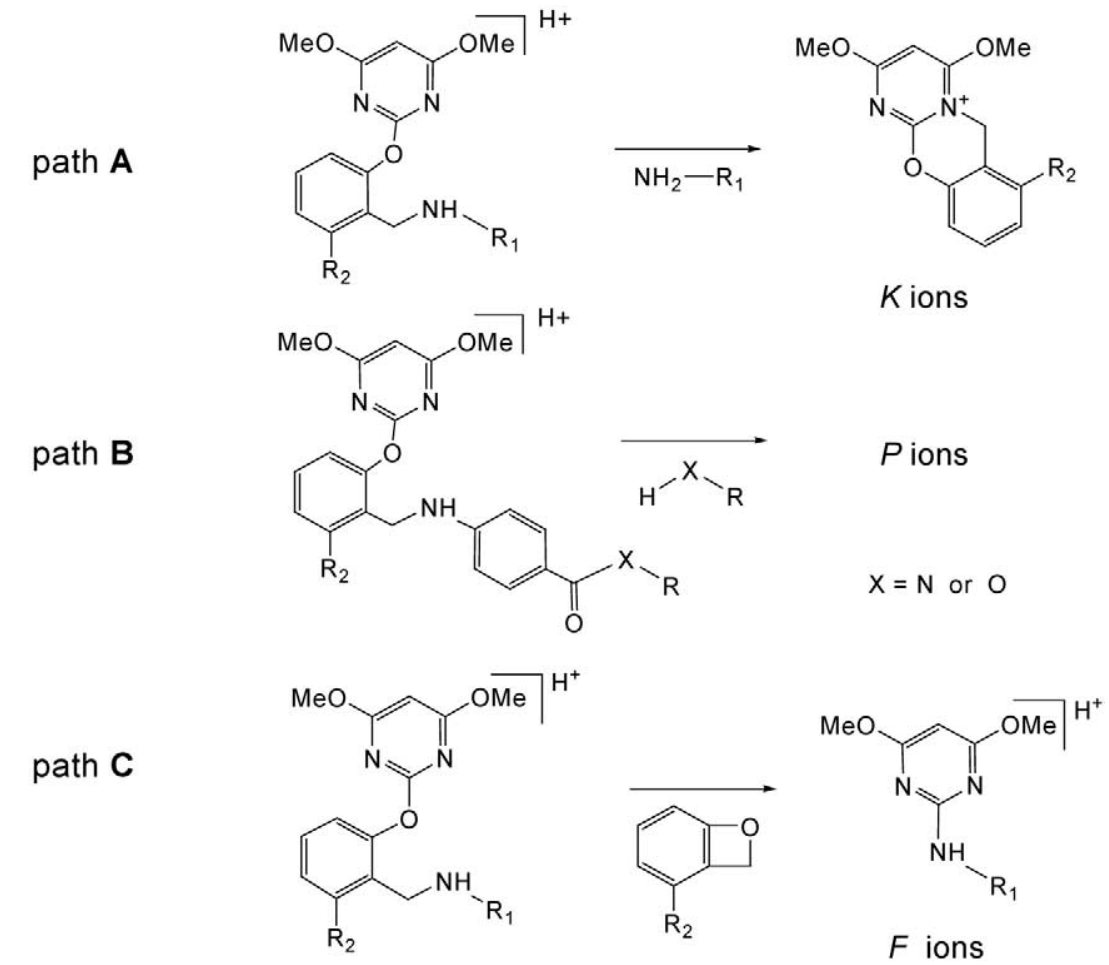

Scheme 2. Proposed three main fragment pathways (A, B, and C) and the structures of the three types of product ions $(K, P$, and $F)$ observed in IRMPD processes of protonated 1 to 8 .

Table 1. Comparison of the results of accurate mass determinations by FTMS and the actual masses for the proposed structures of main product ions of protonated 1 to 8

\begin{tabular}{|c|c|c|c|c|}
\hline Compounds & lons element composition & Mass detected & Actual mass & Relative error (PPM) \\
\hline \multirow[t]{3}{*}{1} & $\mathrm{C}_{23} \mathrm{H}_{26} \mathrm{~N}_{3} \mathrm{O}_{5}$ & 424.1874 & 424.1867 & 1.7 \\
\hline & $\mathrm{C}_{20} \mathrm{H}_{18} \mathrm{~N}_{3} \mathrm{O}_{4}$ & 364.1289 & 364.1292 & -0.8 \\
\hline & $\mathrm{C}_{13} \mathrm{H}_{13} \mathrm{~N}_{2} \mathrm{O}_{3}$ & 245.0912 & 245.0921 & -3.5 \\
\hline \multirow[t]{3}{*}{2} & $\mathrm{C}_{23} \mathrm{H}_{25} \mathrm{~N}_{3} \mathrm{O}_{5} \mathrm{Cl}$ & 458.1495 & 458.1477 & 3.9 \\
\hline & $\mathrm{C}_{20} \mathrm{H}_{17} \mathrm{~N}_{3} \mathrm{O}_{4} \mathrm{Cl}$ & 398.0905 & 398.0902 & 0.7 \\
\hline & $\mathrm{C}_{13} \mathrm{H}_{12} \mathrm{~N}_{2} \mathrm{O}_{3} \mathrm{Cl}$ & 279.0524 & 279.0531 & -2.5 \\
\hline \multirow[t]{3}{*}{3} & $\mathrm{C}_{25} \mathrm{H}_{29} \mathrm{~N}_{4} \mathrm{O}_{4}$ & 449.2172 & 449.2183 & -2.5 \\
\hline & $\mathrm{C}_{20} \mathrm{H}_{18} \mathrm{~N}_{3} \mathrm{O}_{4}$ & 364.1290 & 364.1292 & -0.5 \\
\hline & $\mathrm{C}_{13} \mathrm{H}_{13} \mathrm{~N}_{2} \mathrm{O}_{3}$ & 245.0925 & 245.0921 & 1.6 \\
\hline \multirow[t]{5}{*}{4} & $\mathrm{C}_{24} \mathrm{H}_{28} \mathrm{~N}_{4} \mathrm{O}_{4} \mathrm{Cl}$ & 471.1808 & 471.1794 & 3.0 \\
\hline & $\mathrm{C}_{20} \mathrm{H}_{17} \mathrm{~N}_{3} \mathrm{O}_{4} \mathrm{Cl}$ & 398.0896 & 398.0902 & -1.5 \\
\hline & $\mathrm{C}_{17} \mathrm{H}_{23} \mathrm{~N}_{4} \mathrm{O}_{3}$ & 331.1755 & 331.1765 & -2.9 \\
\hline & $\mathrm{C}_{13} \mathrm{H}_{12} \mathrm{~N}_{2} \mathrm{O}_{3} \mathrm{Cl}$ & 279.0522 & 279.0531 & -3.2 \\
\hline & $\mathrm{C}_{13} \mathrm{H}_{12} \mathrm{~N}_{3} \mathrm{O}_{3}$ & 258.0862 & 258.0873 & -4.3 \\
\hline \multirow[t]{3}{*}{5} & $\mathrm{C}_{18} \mathrm{H}_{18} \mathrm{~N}_{4} \mathrm{O}_{3} \mathrm{Br}$ & 417.0559 & 417.0557 & 0.5 \\
\hline & $\mathrm{C}_{11} \mathrm{H}_{12} \mathrm{~N}_{4} \mathrm{O}_{2} \mathrm{Br}$ & 311.0130 & 311.0138 & -2.6 \\
\hline & $\mathrm{C}_{13} \mathrm{H}_{13} \mathrm{~N}_{2} \mathrm{O}_{3}$ & 245.0911 & 245.0921 & -4.1 \\
\hline \multirow[t]{3}{*}{6} & $\mathrm{C}_{18} \mathrm{H}_{17} \mathrm{~N}_{4} \mathrm{O}_{3} \mathrm{BrCl}$ & 451.0161 & 451.0167 & -1.4 \\
\hline & $\mathrm{C}_{11} \mathrm{H}_{12} \mathrm{~N}_{4} \mathrm{O}_{2} \mathrm{Br}$ & 311.0124 & 311.0138 & -4.5 \\
\hline & $\mathrm{C}_{13} \mathrm{H}_{12} \mathrm{~N}_{2} \mathrm{O}_{3} \mathrm{Cl}$ & 279.0519 & 279.0531 & -4.3 \\
\hline \multirow[t]{2}{*}{7} & $\mathrm{C}_{19} \mathrm{H}_{19} \mathrm{~N}_{3} \mathrm{O}_{3} \mathrm{Br}$ & 416.0617 & 416.0604 & 3.1 \\
\hline & $\mathrm{C}_{13} \mathrm{H}_{13} \mathrm{~N}_{2} \mathrm{O}_{3}$ & 245.0924 & 245.0921 & 1.2 \\
\hline \multirow[t]{3}{*}{8} & $\mathrm{C}_{26} \mathrm{H}_{25} \mathrm{~N}_{4} \mathrm{O}_{4}$ & 457.1885 & 457.1870 & 3.2 \\
\hline & $\mathrm{C}_{26} \mathrm{H}_{23} \mathrm{~N}_{4} \mathrm{O}_{3}$ & 439.1779 & 439.1765 & 3.3 \\
\hline & $\mathrm{C}_{13} \mathrm{H}_{13} \mathrm{~N}_{2} \mathrm{O}_{3}$ & 245.0922 & 245.0921 & 0.4 \\
\hline
\end{tabular}




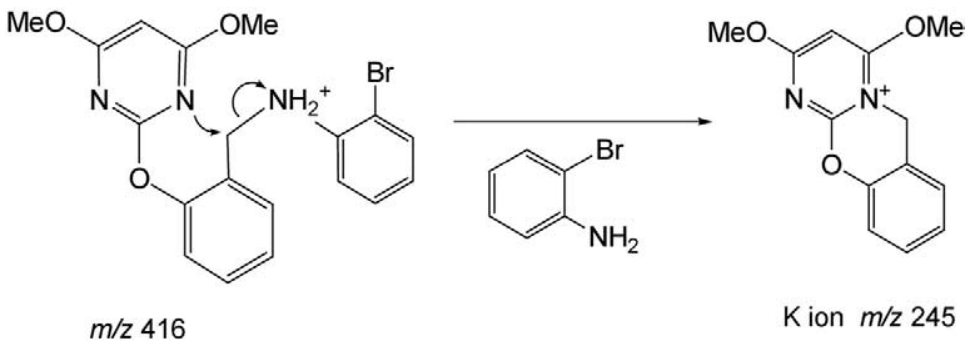

Scheme 3. Formation pathway of $K$ ion at $m / z 245$ from IRMPD of protonated 7 .

$\mathrm{m} / \mathrm{z} 245$ (or 279, when $\mathrm{R}_{2}=\mathrm{Cl}$ ) and the ESI-in-source CAD spectrum of protonated $\mathbf{9}$ (or 10) contains only the ion at $\mathrm{m} / \mathrm{z}$ 311. However, the IRMPD spectrum of protonated 5 (or 6) contains not only the ion at $\mathrm{m} / z 245$ (or 279 , when $\mathrm{R}_{2}=\mathrm{Cl}$ ) but also the ion at $\mathrm{m} / \mathrm{z} 311$. Careful analysis of results from two different dissociation techniques shows that a $S_{N} A r$ type skeletal rearrangement reaction of protonated 5 (or 6) may occur under IRMPD in the FT-ICR cell. During IRMPD, it is proposed that the protonated 5 (or 6 ) ions rearrange to the protonated 9 (or 10) ion, and then dissociate into the $F$ ion at $\mathrm{m} / \mathrm{z} 311$. The rearrangement reaction described in this paper is based on the results of FT-ICR MS.

\section{Experimental}

\section{Materials}

MALDI matrix, 2,5-dihydrobenzoic acid (DHB), was purchased from Sigma (Sigma-Aldrich Co., St. Louis, MO). Water was purified with a Millipore plus system from Millipore (Millipore, ELPaso, TX). Compounds (1 to 10 ) were synthesized and verified by NMR, IR, and MS. All sample solutions were prepared at approximately 1 $\mathrm{mg} / \mathrm{ml}$ with methanol. For lithium adduct experiments, the $0.5 \mathrm{mM} \mathrm{LiCl}$ solution was added to the sample solution. The DHB matrix solution was deposited onto the probe tip using Eppendrof GEL loader pipette tips (Brinkermann Instruments Inc., Westbury, NY) produced microcrystalline layers of matrix, followed by sample deposition onto the preformed matrix layer. Samples and DHB were dissolved in the $\mathrm{D}_{4^{-}}$methanol in the $\mathrm{H}-\mathrm{D}$ exchange experiment.

\section{MALDI-IRMPD Analysis}

The experiments were performed on a FT-ICR MS (Ionspec, Irvine, CA) equipped with a $4.7 \mathrm{~T}$ actively shielded super-conducting electromagnet (Cryomagnetics, Oak Ridge, TN). The external Ionspec MALDI ion source used an air-cooled ND:YAG laser $(355 \mathrm{~nm}$, New Wave, Fremont, CA) with a gradient filter for adjusting the UV-laser power. Ions, generated from a MALDI source, were transferred via a quadrupole ion guide to the capacitively coupled closed cylindrical cell.

Ions of interest were isolated using the arbitrary waveform generator, with parameters adjusted to eject unwanted ions (including the isotopic peak) with minimal loss of the intended precursor ion. The arbitrary amplitude was set to $60 \mathrm{~V}_{b-p}$ and the mass isolation window was set as $0.8 \mathrm{~m} / \mathrm{s}$ to eliminate the unwanted ions, so all masses listed here and throughout the paper are the masses of the monoisotopic peak.

IRMPD experiments were performed with a model SYNRAD series $48 \mathrm{CO}_{2}$ laser (75 MAX). The intensity of IRMPD laser irradiation was varied between $50 \sim 100 \%$ as needed at a flux of $75 \mathrm{~W} / \mathrm{cm}^{2}$. The IRMPD laser irradiation pulse time was set as $500 \mathrm{~ms}$ for protonated compounds and $1500 \mathrm{~ms}$ for lithium-cationized compounds to give sufficient energy and time for dissociation. The SORI-CAD experiments were also performed and the results show no obvious differences between IRMPD and SORI-CAD. Therefore the SORI-CAD experiments are not discussed further.

\section{ESI In-Source CAD Analysis}

The ESI in-source CAD (Collision Induced Dissociation in ESI ion source) experiments were performed with a quadruple mass spectrometer (Agilent LCMSD-SL, Agilent Technologies, Palo Alto, CA). The spray tip potential was set to $4000 \mathrm{~V}$. The nebulizing gas flow rate and curtain gas pressure were $10 \mathrm{ml} \mathrm{min}{ }^{-1}$ and $35 \mathrm{psi}$, respectively. The fragmentation voltage was set at $250 \mathrm{~V}$ to give sufficient energy for dissociation.
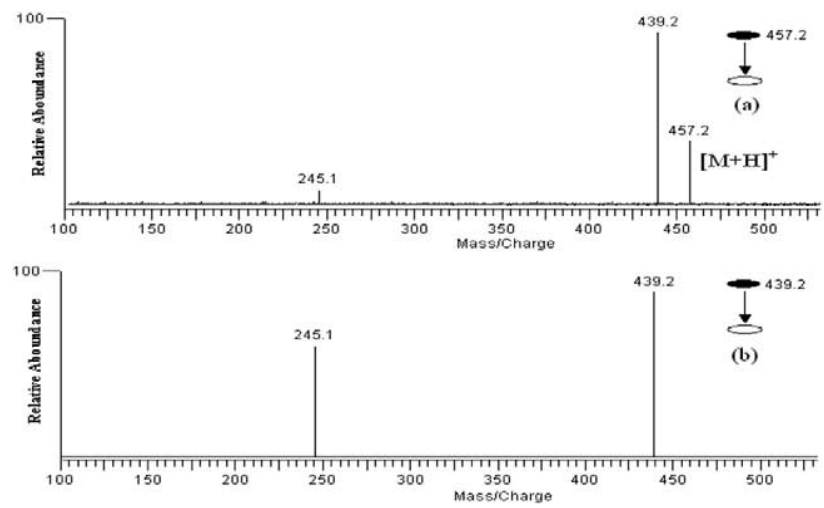

Figure 2. The IRMPD spectra of protonated 8 and the ion at $\mathrm{m} / \mathrm{z}$ 439: (a) Protonated 3 at $\mathrm{m} / \mathrm{z}$ 457; (b) the ion at $\mathrm{m} / \mathrm{z} 439$. 


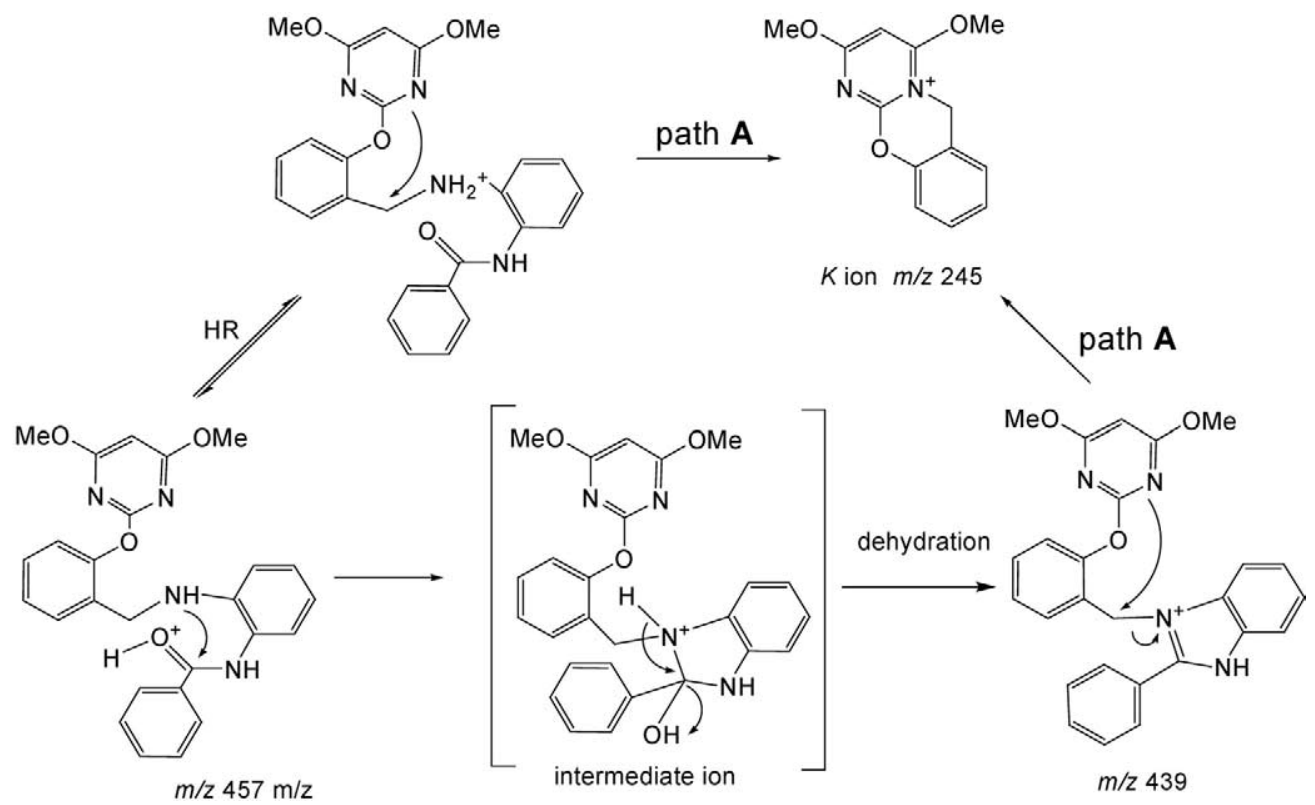

Scheme 4. Formation pathways of the ion at $m / z 245$ and 439 from IRMPD of protonated 8 .

\section{Results and Discussion}

\section{IRMPD of Protonated 2-Pyrimidinyloxy-N- Arylbenzylamine Derivatives}

IRMPD is a general method for activating ions trapped in a FT-ICR cell to generate fragment ions and is frequently used for structural analysis and gas-phase chemistry research. The IRMPD spectra of protonated 2-pyrimidinyloxy-N-arylbenzylamine derivatives obtained using IonSpec FT-ICR MS are depicted in Figure 1. According to the IRMPD data, three major dissociation pathways (A, B, and C) and the structures of three major types of product ions $(K, P$, and $F)$ from IRMPD of the protonated compounds are proposed and shown in Scheme 2. The structures of the product ions are fully supported by the accurate mass measurements obtained using FT-ICR MS. Table 1 shows a comparison of the masses determined and the actual masses of the proposed structures, and the corresponding element composites of the main fragment ions. The relative errors are all less than 5 ppm, so the results indicate that the proposed structures have the only reasonable elemental compositions. The mechanisms of these pathways will be discussed in detail below.

\section{Migration of Benzyl Group Initiated by Intramolecular $S_{N} 2$ Reaction}

Analyses revealed that the protonated 1 to 8 can all undergo Pathway A to produce the characteristic ion series of these compounds, the $K$ ion series at $m / z 245$ (or 279 , when $\mathrm{R}_{2}=\mathrm{Cl}$ ). Protonated 7 is selected to illustrate Pathway $\mathbf{A}$, which is the only dissociation Pathway of protonated 7. The mechanism of this rearrangement is proposed to be a gas-phase intramolecular nucleophilic displacement reaction $\left(\mathrm{S}_{\mathrm{N}} 2\right)$ and is shown in Scheme 3.
The tertiary amine of pyrimidine attacks the benzylic carbon as the nucleophile and the protonated phenyl amine act as a leaving group, which leads to the formation of the ion at $m / z 245$ by the cleavage of the $\mathrm{C}-\mathrm{N}$ bond connecting the benzylic carbon and phenyl amine. This rearrangement (migration of the benzylic group from phenyl amine to pyrimidine amine) is similar to the rearrangement of farnesyl transferase inhibitor [10]. Such a $S_{N} 2$ reaction is facilitated by the fact that pyrimidine is a gas-phase nucleophile and protonated phenyl amine is a gas-phase leaving group. The mass of the $K$ ion series can give useful information about the $R_{2}$ substituent group.

\section{An Interesting Intramolecular Dehydration Reaction of Protonated 8}

The IRMPD spectrum of protonated 8 contains two product ions at $m / z 245$ and 439 . The accurate mass determination result shows that the ion at $m / z 439$ arises by dehydration from protonated 8 . To investigate this process, the IRMPD spectrum of the ion at $m / z 439$ was obtained and shown in Figure 2, which contains only one product ion at $\mathrm{m} / \mathrm{z} 245$. Therefore, the structural unit,

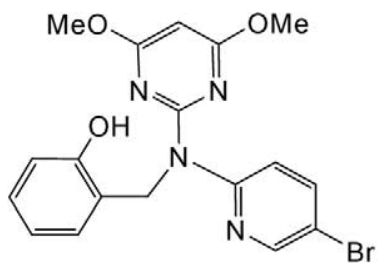

$9 \quad$ M.W. 416

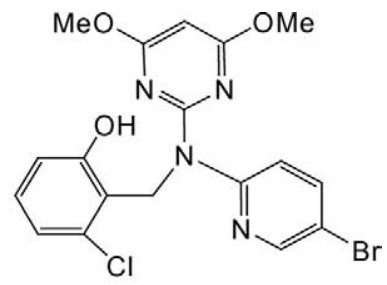

10 M.W. 450
Scheme 5. The chemical structure of $\mathbf{9}$ and $\mathbf{1 0}$ (molecular weight in Da.). 

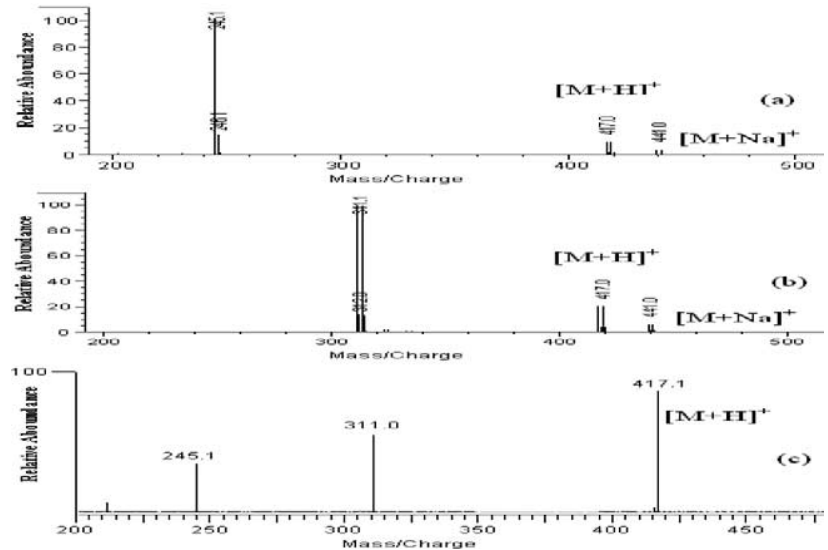

Figure 3. Comparison of the product ion spectra between insource CAD and IRMPD: (a) The in-source CAD spectrum of protonated 5 at $\mathrm{m} / \mathrm{z} 417$; (b) the in-source CAD spectrum of protonated 9 at $\mathrm{m} / \mathrm{z} 417$; (c) the IRMPD spectrum of protonated 5 at $m / z 417$.

which can produce the $K$ ion at $m / z 245$, must remain unchanged during the dehydration process. The two competitive rearrangement/ fragmentation mechanisms of protonated 8 are shown in Scheme 4. The interesting dehydration process contains two steps. First, H rearranges from arylbenzylamine to the carbonyl of amide. In the second step, the arylbenzylamine adds to the protonated carbonyl of amide as the nucleophile to form the unstable intermediate ion; the hydroxyl of the intermediate ion is protonated, which gives rise to the iminium ion at $m / z 439$ by loss of $\mathrm{H}_{2} \mathrm{O}$. The iminium ion at $m / z 439$ has a benzoimidazole structure. In the IRMPD of the ion at $\mathrm{m} / \mathrm{z}$ 439 , the pyrimidine amine attacks the benzylic carbon and the benzoimidazole type iminium ion acts as a good leaving group to form the $K$ ion at $m / z 245$ by cleavage of the $\mathrm{C}-\mathrm{N}$ bond connecting the benzylic carbon and the benzoimidazole amine.

\section{Rearrangement of Protonated 5 and 6 Promoted by Intramolecular $S_{N}$ Ar Reaction}

The IRMPD spectrum of protonated 5 (or 6 ) shows that protonated 5 (or 6) has two competitive rearrangement pathways: (1) Pathway $\mathbf{A}$, which gives rise to the $K$ ion series at $m / z 245$ (at $m / z 279$, when $R_{2}=C l$ ); (2) Pathway $C$, which gives rise to the $F$ ion at $m / z$ 311. The formation of $F$ ion at $m / z 311$ cannot be rationalized without invoking skeletal rearrangement.

The recent finding during LC-MS studies of the degradation products of 5 and 6 provides a valuable clue about the formation pathway of the $F$ ion at $\mathrm{m} / \mathrm{z}$ 311. Our recent studies showed that the 2-pyrimidinyloxy- $N$-arylbenzylamine derivatives could undergo rearrangement during chemical degradation. Compounds $\mathbf{9}$ and $\mathbf{1 0}$ are the rearrangement products of 5 and 6 , respectively. The chemical structures of Compounds $\mathbf{9}$ and $\mathbf{1 0}$ are shown in Scheme 5. Insource CAD was used to obtain structural informa- tion for the compounds in the LC-MS analysis. To our surprise, the ion at $m / z 245$ (or 279 , when $\mathrm{R}_{2}=\mathrm{Cl}$ ) is the only product ion from ESI in-source CAD of protonated 5 (or 6). Furthermore, protonated 9 (or 10) gives the product ion at $m / z 311$ from ESI in-source CAD, which is consistent with the $F$ ion at $m / z 311$ from IRMPD of protonated 5 (or 6). The ESI insource-CAD spectra of protonated 5 (and 6) and protonated 9 (and 10) and IRMPD spectra of protonated 5 (and 6) are shown in Figures 3 and 4, respectively. These results, obtained from two dissociation techniques, shed light on the mechanism of Pathway C. It is proposed that the formation pathway of the $F$ ion at $m / z 311$ under IRMPD in the FT-ICR cell is that the protonated 5 (or 6 ) first rearranges to protonated 9 (or 10), and then dissociates into the ion at $m / z 311$.

The different timescales of the two dissociation techniques can be used to explain the difference in the product ion spectra. During the in-source CAD process, the ions generated by ESI were immediately transferred via collision skimmer to the quadrupole mass detector. Generally, the product ions of in-source CAD reflect the structure of precursor ion and the original charge site of the ion. However, the comparatively long duration of IRMPD allows the proton of the activated protonated ion to migrate to other basic sites, which can provide alterative rearrangement/fragmentation pathways. All the information mentioned above shows that protonated 5 and 6 could undergo rearrangement during IRMPD, just as the rearrangement reaction occurs in the condensed phase.

A two-step mechanism is proposed to explain Pathway C. In the first step, protonated 5 (or 6 ) rearranges to protonated 9 (or 10). It is proposed that this rearrangement is initiated by a gas-phase intramolecular aromatic addition and elimination reaction $\left(S_{N} A r\right)$ [20]. This $\mathrm{S}_{\mathrm{N}} \mathrm{Ar}$ type rearrangement mechanism is shown in Scheme 6. In this process, $\mathrm{H}$ migrates from the arylbenzylamine group to the neighboring pyridine amine, so

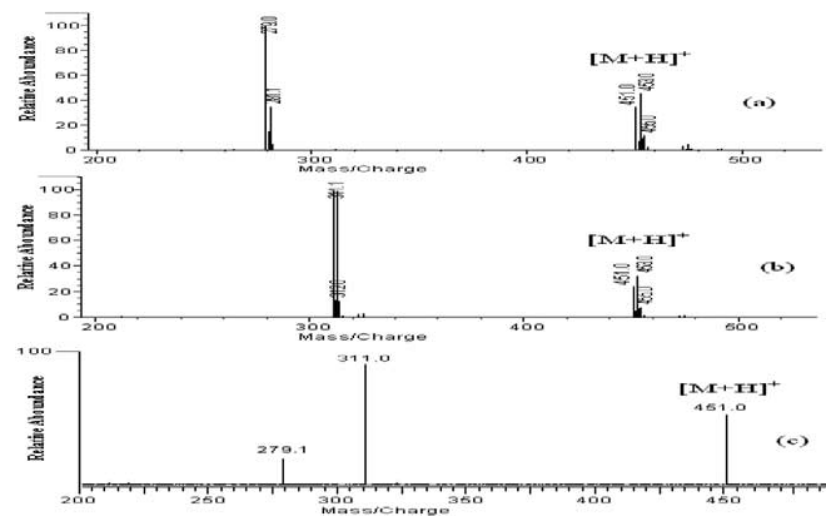

Figure 4. Comparison of the product ion spectra between insource CAD and IRMPD: (a) the in-source CAD spectrum of protonated 6 at $\mathrm{m} / \mathrm{z} 451$; (b) the in-source CAD spectrum of protonated 10 at $\mathrm{m} / \mathrm{z} 451$; (c) the IRMPD spectrum of protonated 6 at $m / z 451$. 

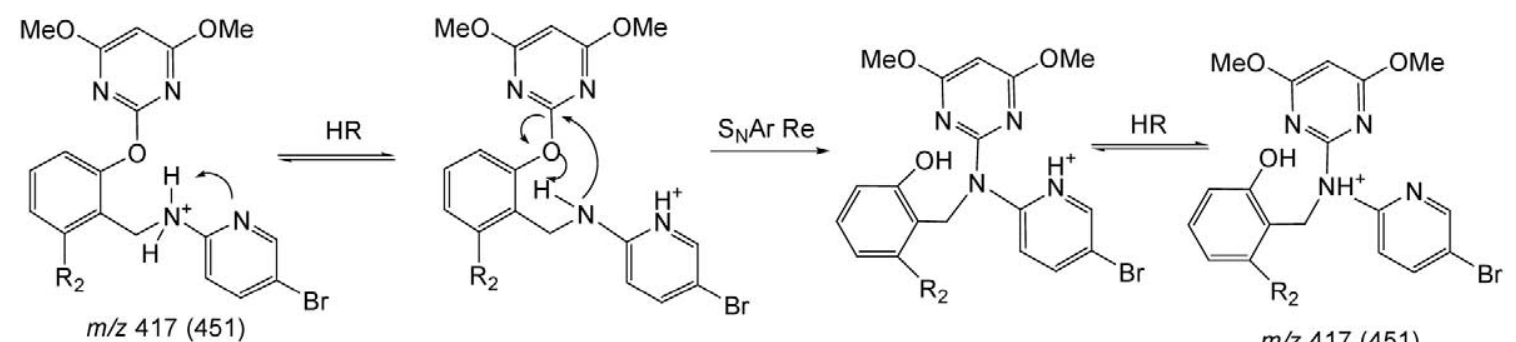

Scheme 6. The mechanism of the $S_{N} A r$ type rearrangement.

$\mathrm{m} / \mathrm{z} 417$ (451)

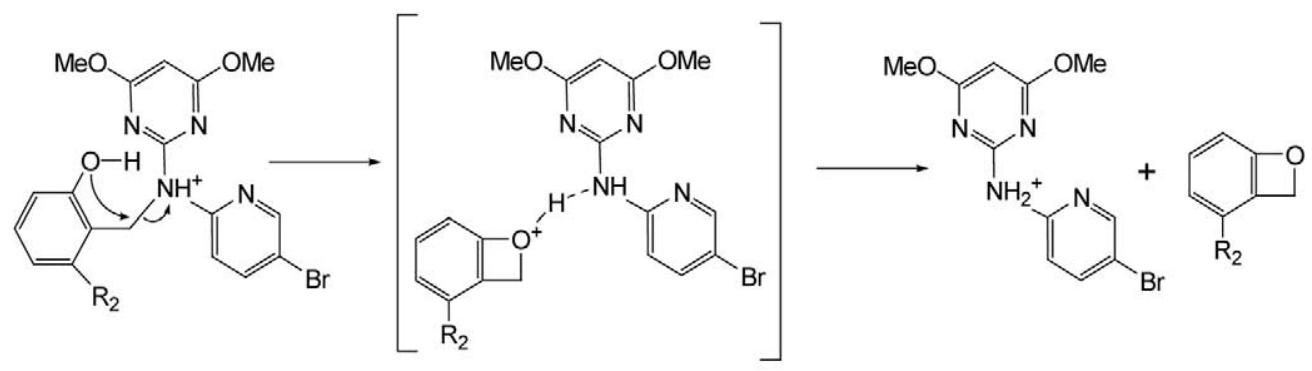

$m / z 417(451)$

Ion-neutral Complex

Fion $m / z 311$

Scheme 7. Formation pathway of the $F$ ion at $m / z 311$ from IRMPD of protonated 9 (or 10). The data in parentheses are those observed, when $\mathrm{R}_{2}$ is $\mathrm{Cl}$ substitute group.

the neutral arylbenzylamine group can attack the 6-position carbon of pyrimidine as the nucleophile; simultaneously, cleavage of the $\mathrm{C}-\mathrm{O}$ bond occurs with the $\mathrm{H}$ migration from the arylbenzylamine to the phenol oxygen to form the phenol hydroxyl group of protonated 9 (or 10).

The second step is the formation of the $F$ ion at $\mathrm{m} / \mathrm{z}$ 311 from protonated 9 (or 10). Ion-neutral complexes are invoked to explain this pathway. This mechanism is shown in Scheme 7. Ion-neutral complexes have been increasingly proposed as important intermediates in unimolecular fragmentation/rearrangement in MS/MS [13]. The ion-neutral complex is formed after an intramolecular $\mathrm{S}_{\mathrm{N}} 2$ reaction. In this $\mathrm{S}_{\mathrm{N}} 2$ reaction, the oxygen of phenol hydroxyl group attacks the benzylic carbon as the nucleophile and the protonated phenyl amine acts as a leaving group; this induces cleavage of the $\mathrm{C}-\mathrm{N}$ bond connecting the benzylic carbon and protonated phenyl amine to form the ion-neutral complexes. In this ion-neutral complex, the protonated phenol ether is bonded to phenyl amine by hydrogen bonding, and then $\mathrm{H}$ rearrangement from the protonated phenol ether to phenyl amine occurs to form the $F$ ion at $\mathrm{m} / \mathrm{z} 311$.

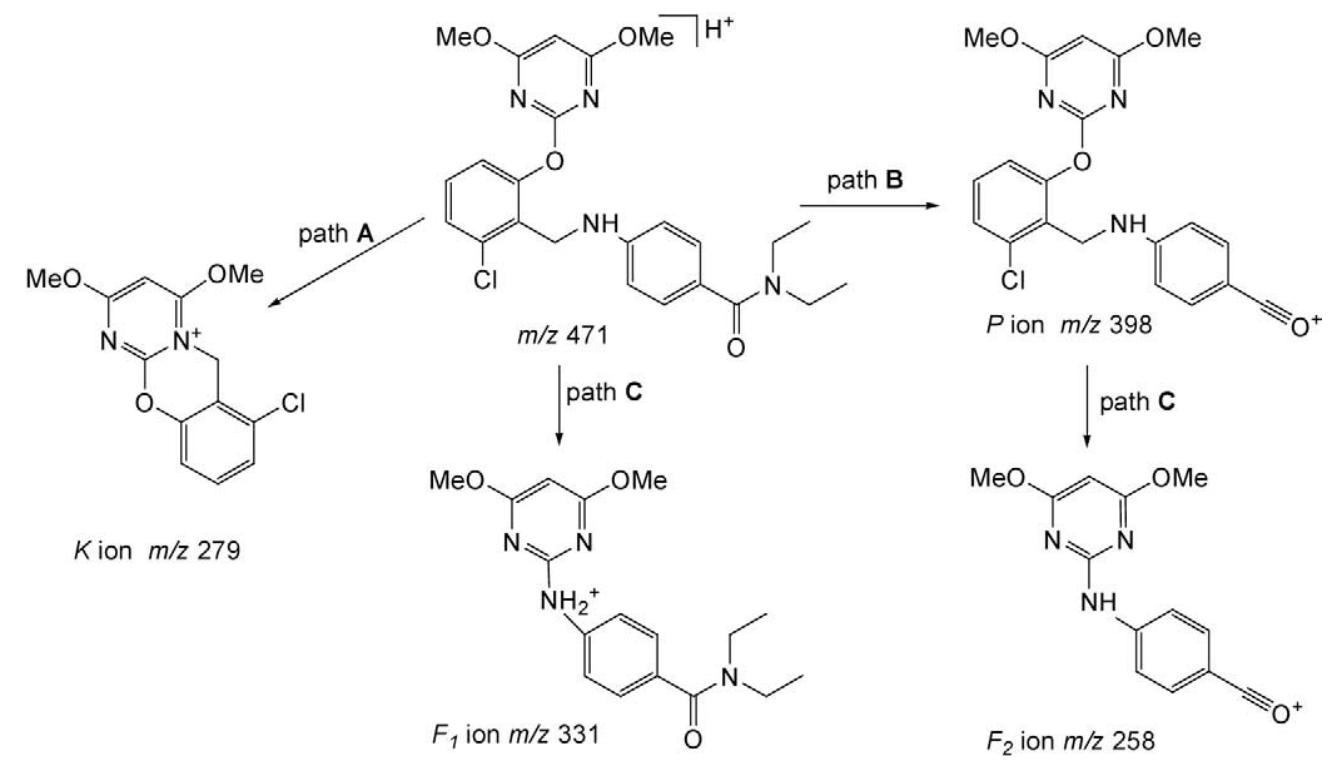

Scheme 8. Formation pathways of the ions at $m / z 331,258$, and 398 from IRMPD of protonated 4. 


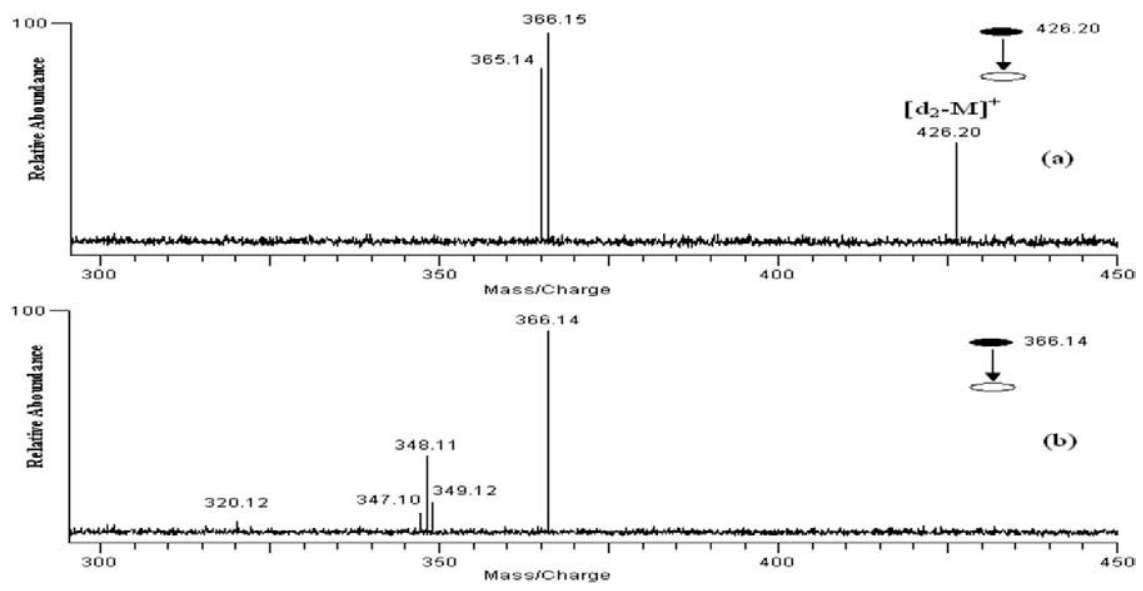

Figure 5. The IRMPD spectra of deuterated 1 and the ion at $\mathrm{m} / \mathrm{z}$ 366: (a) deuterated 1 at $\mathrm{m} / \mathrm{z}$ 426; (b) the ion at $m / z 366$.

Compared with 5, 6 has a chlorine substituent at C-6 of the benzene of benzylamine, so the chlorine substituent can be regarded as a marker to support the rearrangement process.

However, the reason that 5 (or 6) can undergo this reaction to such a great extent can be explained as follows: 5 and 6 have a tertiary amine of pyridine as neighboring functional groups of arylbenzylamine with similar PA (proton affinity); therefore, the $\mathrm{H}$ migration can readily occur to release the neutral arylbenzylamine as a nucleophile to induce the $S_{N} A r$ type gas-phase rearrangement. When no other neighboring functional group is available to accept $\mathrm{H}$, Pathway A will be the dominant dissociation process, just as for compound 7. Protonated 4 can also undergo Pathway $C$ to form $F$ ions (at $\mathrm{m} / \mathrm{z} 331$ ). The proposed mechanism of this process is shown in Scheme 8. The amide group of Compound 4 plays a similar role as the tertiary amine of the pyridine group in 5 (or 6 ) to stabilize the proton. However, it is only a minor process compared with the rearrangement reaction of protonated 5 and 6 , because of the long distance between the arylbenzylamine and amide group in Compound 4 .

\section{Gas-Phase Cope Type Rearrangement of P Ions from Protonated 1 and $\mathbf{2}$}

Pathway B involves loss of a neutral molecule. The protonated 1, 2, 3, and 4 ions can undergo the Pathway $\mathrm{B}$ produce the $P$ ion at $\mathrm{m} / \mathrm{z} 364$ (or 398, when $\mathrm{R}_{2}=\mathrm{Cl}$ ). Of note is the finding that the IRMPD spectra of the $P$ ion at $\mathrm{m} / \mathrm{z} 364$ (or 398, when $\mathrm{R} 2=\mathrm{Cl}$ ) from protonated 1 (or 2), show abundant peaks of the $W$ ion series by an $\mathrm{NH}_{3}$ elimination pathway. The assignment of $W$ ions was supported by comparison between the average mass shift from $P$ ions $(17.0263 \mathrm{Da})$ and the accurate mass of $\mathrm{NH}_{3}$ (17.0265 Da). This $\mathrm{NH}_{3}$ elimination pathway is an unusual process for the $P$ ions, so the formation of the $W$ ions was more fully explored. To reveal the whole process, the MS/MS spectra of the deuterium-labeled molecule $\left(D_{2}-1\right)$ at $m / z 426$ and the ion at $m / z 366$ were obtained by H-D

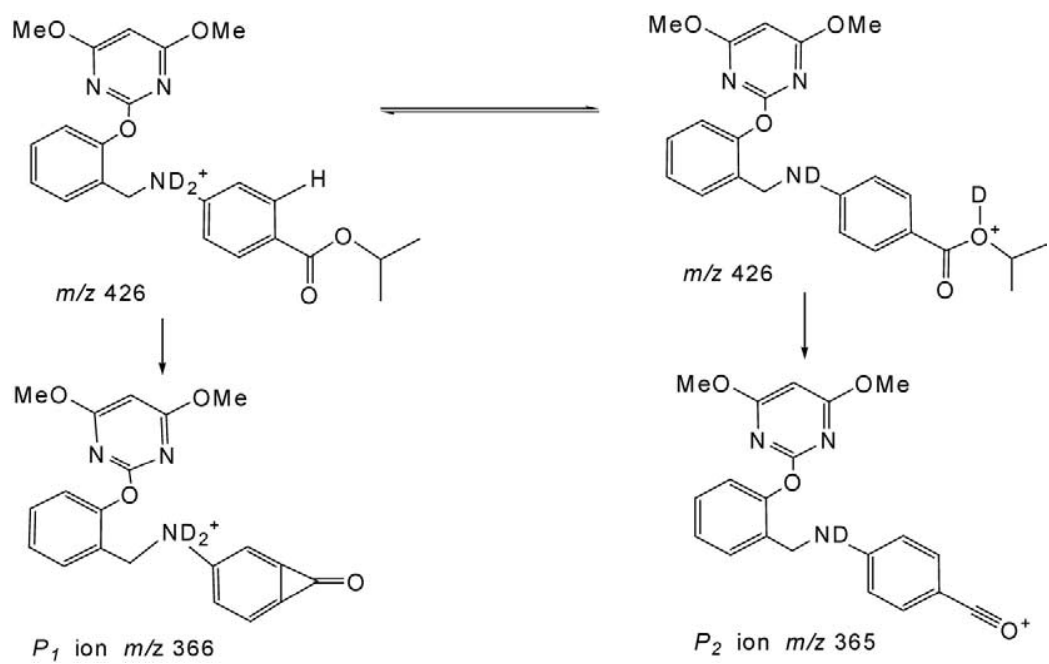

Scheme 9. Formation pathways of $P_{1}$ ion and $P_{2}$ ion from IRMPD of $\left[\mathrm{D}_{2}+1\right]^{+}$. 


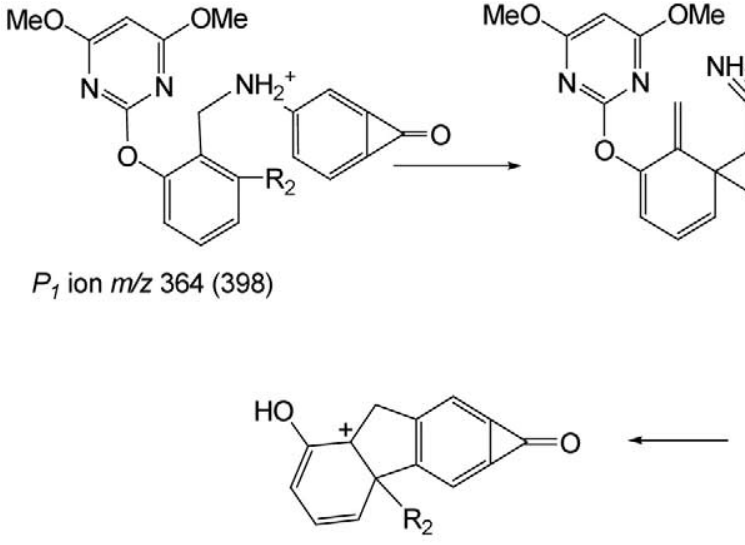

$U$ ion $m / z$ 209(243)

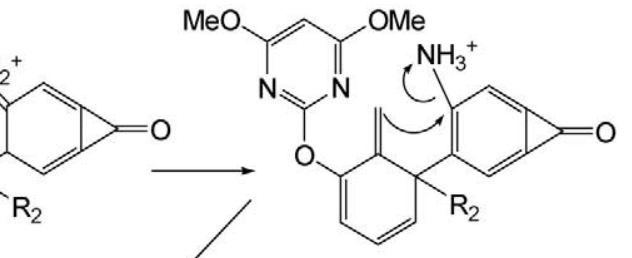<smiles>[R2]C12C=CC=C(Oc3nc(OC)c(C)c(OC)n3)C1Cc1ccccc1C2=O</smiles>

Wion $\mathrm{m} / \mathrm{z} 347(381)$<smiles>[R16]CCCCCCCC1([R2])C=CC=C(Oc2nc(OC)cc(OC)n2)[C@@H]1Cc1ccccc1</smiles>

$Y$ ion $m / z 319(353)$

Scheme 10. Formation pathways of the $W$ ion series, $U$ ion series and $Y$ ion series from IRMPD of protonated $P$ ion series. The data in parentheses are those observed, when $R_{2}$ is $\mathrm{Cl}$ substitute group.

exchange experiments and shown in Figure 5. The two product ions at $\mathrm{m} / \mathrm{z} 365$ and $\mathrm{m} / \mathrm{z} 366$ show that the $P$ ions may have two different structures, the $P_{1}$ ions and the $P_{2}$ ions. The proposed mechanism and the structures of the $P_{1}$ ions and the $P_{2}$ ions are shown in Scheme 9. The $P_{1}$ ion at $m / z 366$ is formed, when $\mathrm{H}$ to form propan-2-ol comes from the ortho-position $\mathrm{H}$ of the benzene. The $P_{2}$ ion at $\mathrm{m} / \mathrm{z} 365$ is formed, when D is located at the oxygen of the ester.

The $\mathrm{ND}_{2} \mathrm{H}$ loss pathway from the ion at $\mathrm{m} / \mathrm{z} 366$ shows that the nitrogen of neutral $\mathrm{NH}_{3}$ loss is from the nitrogen of arylbenzylamine. But the source of the $\mathrm{H}$ in the $\mathrm{ND}_{2} \mathrm{H}$ is the most important clue to illustrate the $\mathrm{NH}_{3}$ elimination process. There is no active $\mathrm{H}$ near the arylbenzylamine, so a complicated rearrangement process may be involved. A gas-phase Cope type rearrangement [21-25] is proposed to explain the formation of the $W$ ion and the proposed rearrangement mechanism is shown in Scheme 10. The $\mathrm{NH}_{3}$ elimination process contains two steps. The first step is an atypical gasphase Cope rearrangement process. In this process, a new $\mathrm{C}-\mathrm{C}$ bond connecting two aromatic rings is formed, and simultaneously, the $\mathrm{C}-\mathrm{N}$ bond connecting benzylic carbon and protonated phenyl amine is broken, which occurs with the migration of double bonds. In the second step, the $\mathrm{H}$ rearrangement leads to the formation of protonated aniline, and then the $\mathrm{NH}_{3}$ elimination occurs with the bonding of the benzylic carbon to the neighboring benzene to form the $W$ ion.

The IRMPD spectrum of the $P_{1}$ ion at $\mathrm{m} / \mathrm{z} 364$ from protonated 1 and IRMPD spectrum of the $P_{1}$ ion at $\mathrm{m} / \mathrm{z}$ 398 from protonated 2 is shown in Figure 6 . The $P_{1}$ ions from two compounds were dissociated at the same the energy, the relative abundance of the $W$ ion $(31 \%)$ of 1 is higher than the relative abundance of the $W$ ion $(20 \%)$ of 2 . This occurs since the steric hindrance caused by chlorine substitution at C- 6 of the benzene blocks the Cope type rearrangement process, which in turn shows that the rearrangement process is reasonable. The $U$ ions at $\mathrm{m} / \mathrm{z} 209$ (or 243, when $\mathrm{R}_{2}=\mathrm{Cl}$ ), which are generated by loss of pyrimidine from the $W$ ions and the $Y$ ion at $m / z 319$ (or 353, when $\mathrm{R}_{2}=\mathrm{Cl}$ ), which are generated by loss of $\mathrm{CO}$, can also be used to support the formation process of the $W$ ions.
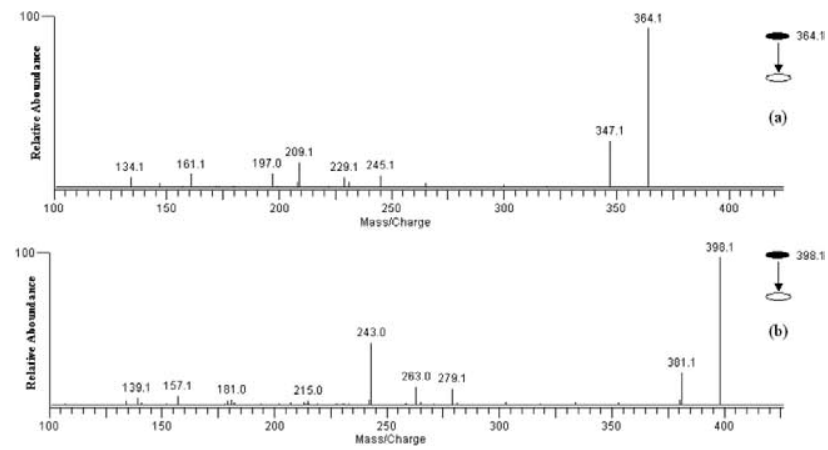

Figure 6. The IRMPD spectra of the $P$ ion from protonated 1 and protonated 2: (a) The ion at $m / z 364$ from protonated 1; (b) the ion at $\mathrm{m} / \mathrm{z} 398$ from protonated 1 . 

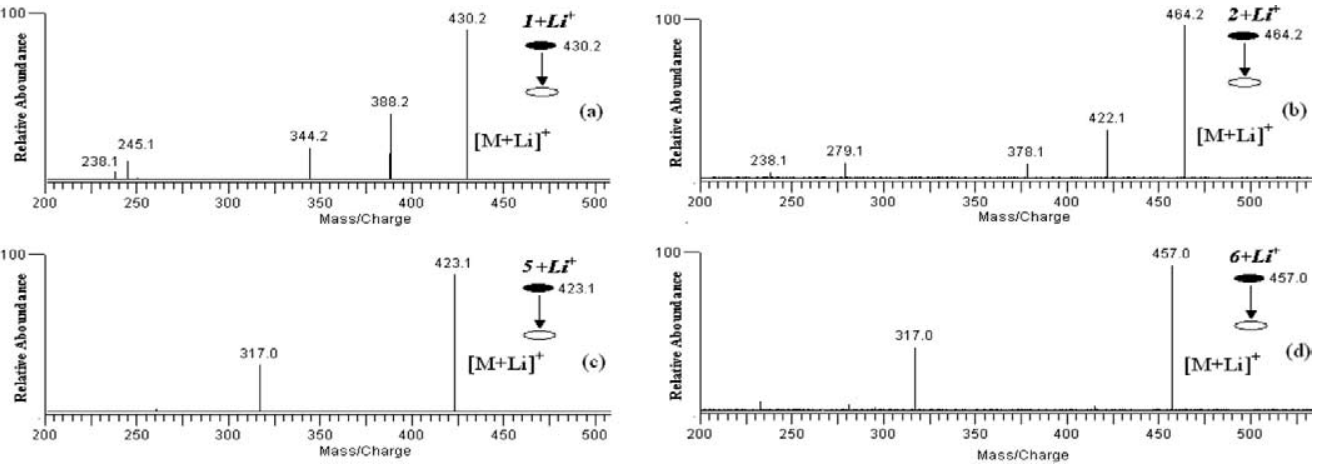

Figure 7. The IRMPD spectra of lithium-cationized 1, 2, 5 and 6: (a) lithium-cationized 1 at $\mathrm{m} / \mathrm{z}$ 430; (b) lithium-cationized 2 at $\mathrm{m} / \mathrm{z} 464$; (c) lithium-cationized 5 at $\mathrm{m} / \mathrm{z} 423$; (d) lithium-cationized 6 at $\mathrm{m} / \mathrm{z}$ 457.

\section{IRMPD of Lithium-Cationized 2-Pyrimidinyloxy- N-Arylbenzylamine Derivatives}

Alkali metal cationization has been explored in recent years as an alternative to protonation to change the site of charge localization and promote different fragmentation processes $[19,26]$. In the presence of alkali metal ions, MALDI spectra of these compounds yield abundant adduct ions; however, only the lithiated adduct ions of 1, 2, 5, and 6 yield informative fragment ions for structural determination. The spectra are shown in Figure 7. The analysis of IRMPD data of the lithium cationized compounds shows the major pathways mentioned above are still useful for interpreting the product ions. The proposed structures of the product ions are supported by the accurate mass determinations. Table 2 shows a comparison of the masses determined and the actual masses of the proposed structures, and the corresponding elemental compositions of the main fragment ions. The relative errors are all less than $5 \mathrm{ppm}$, so the results indicate the proposed structures of the product ions have the only reasonable elemental compositions.

\section{Multi-Stage IRMPD of Lithium-Cationized 1 and $\mathbf{2}$}

The effect of lithium cationization on the dissociation of lithium cationized $\mathbf{1}$ (or 2) is striking. There are two notable changes in the dissociation pattern of lithiumcationized 1 (or 2). First, the IRMPD spectrum of lithium-cationized 1 (or 2) shows more fragment ions, presumably since the lithium ion changes the site of charge localization and the coordination effect of lithium ion promotes different fragmentation processes [19]. The ion generated from the loss of propene at $\mathrm{m} / \mathrm{z}$ 388 (or 422 , when $\mathrm{R}_{2}=\mathrm{Cl}$ ) and the ion formed by further loss of $\mathrm{CO}_{2}$ at $m / z 344$ (or 378, when $\mathrm{R}_{2}=\mathrm{Cl}$ ), were observed with high abundance instead of the ion from loss of propan-2-ol seen for protonated 1 (or 2). Second, the ions at $m / z 238$ arising from Pathway $\mathbf{C}$ can be observed in the IRMPD spectrum of lithium-containing ions at $m / z 344$ (or 378, when $\mathrm{R}_{2}=\mathrm{Cl}$ ). Interestingly, the formation of the $K$ ion at $m / z 245$ (or 279 , when $\mathbf{R}_{2}=$ $\mathrm{Cl}$ ) can still be observed in the IRMPD spectrum of lithium-cationized 1 (or 2). However, this pathway is minor compared with that of protonated 1 (or 2). The genealogical relationships of dissociation of lithium-

Table 2. Comparison of the results of accurate mass determinations by FTMS and the actual masses for the proposed structures of main product ions of lithium-cationized compounds 1, 2, 5, and 6

\begin{tabular}{|c|c|c|c|c|}
\hline Compounds & Ions element composition & Mass detected & Actual mass & Relative error (PPM) \\
\hline \multirow[t]{5}{*}{1} & $\mathrm{C}_{23} \mathrm{H}_{25} \mathrm{~N}_{3} \mathrm{O}_{5} \mathrm{Li}$ & 430.1956 & 430.1949 & 1.7 \\
\hline & $\mathrm{C}_{20} \mathrm{H}_{19} \mathrm{~N}_{3} \mathrm{O}_{5} \mathrm{Li}$ & 388.1483 & 388.1479 & 1.0 \\
\hline & $\mathrm{C}_{19} \mathrm{H}_{19} \mathrm{~N}_{3} \mathrm{O}_{3} \mathrm{Li}$ & 344.1581 & 344.1581 & 0.0 \\
\hline & $\mathrm{C}_{13} \mathrm{H}_{13} \mathrm{~N}_{2} \mathrm{O}_{3}$ & 245.0913 & 245.0921 & -3.1 \\
\hline & $\mathrm{C}_{12} \mathrm{H}_{13} \mathrm{~N}_{3} \mathrm{O}_{2} \mathrm{Li}$ & 238.1155 & 238.1162 & -3.1 \\
\hline \multirow[t]{5}{*}{2} & $\mathrm{C}_{23} \mathrm{H}_{24} \mathrm{~N}_{3} \mathrm{O}_{5} \mathrm{ClLi}$ & 464.1560 & 464.1559 & 0.2 \\
\hline & $\mathrm{C}_{20} \mathrm{H}_{18} \mathrm{~N}_{3} \mathrm{O}_{5} \mathrm{ClLi}$ & 422.1096 & 422.1090 & 1.5 \\
\hline & $\mathrm{C}_{19} \mathrm{H}_{18} \mathrm{~N}_{3} \mathrm{O}_{3} \mathrm{ClLi}$ & 378.1198 & 378.1191 & 1.8 \\
\hline & $\mathrm{C}_{13} \mathrm{H}_{12} \mathrm{~N}_{2} \mathrm{O}_{3} \mathrm{Cl}$ & 279.0536 & 279.0531 & 1.8 \\
\hline & $\mathrm{C}_{12} \mathrm{H}_{13} \mathrm{~N}_{3} \mathrm{O}_{2} \mathrm{Li}$ & 238.1166 & 238.1162 & 1.6 \\
\hline \multirow[t]{2}{*}{5} & $\mathrm{C}_{18} \mathrm{H}_{17} \mathrm{~N}_{4} \mathrm{O}_{3} \mathrm{BrLi}$ & 423.0645 & 423.0639 & 1.5 \\
\hline & $\mathrm{C}_{11} \mathrm{H}_{11} \mathrm{~N}_{4} \mathrm{O}_{2} \mathrm{BrLi}$ & 317.0209 & 317.0220 & -3.4 \\
\hline \multirow[t]{2}{*}{6} & $\mathrm{C}_{18} \mathrm{H}_{16} \mathrm{~N}_{4} \mathrm{O}_{3} \mathrm{BrClLi}$ & 457.0261 & 457.0249 & 2.6 \\
\hline & $\mathrm{C}_{11} \mathrm{H}_{11} \mathrm{~N}_{4} \mathrm{O}_{2} \mathrm{BrLi}$ & 317.0232 & 317.0220 & 3.8 \\
\hline
\end{tabular}



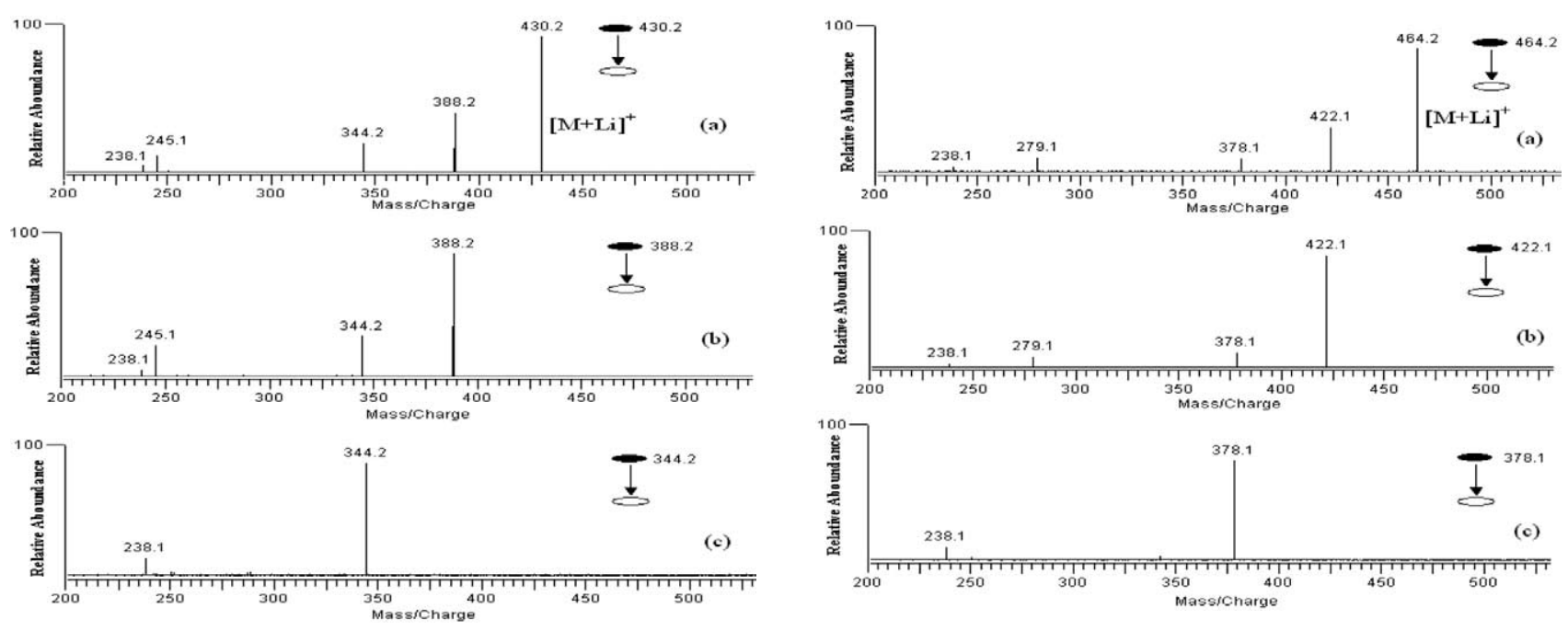

Figure 8. The IRMPD spectra of lithium-cationized 1, the ion at $\mathrm{m} / \mathrm{z} 388$ and the ion at $\mathrm{m} / \mathrm{z}$ 344: (a) Lithium-cationized 1 at $\mathrm{m} / \mathrm{z}$ 430; (b) the ion at $\mathrm{m} / \mathrm{z} 388$; (c) the ion at $\mathrm{m} / \mathrm{z} 344$.

Figure 9. The IRMPD spectra of lithium-cationized 2, the ion at $\mathrm{m} / \mathrm{z} 422$ and the ion at $\mathrm{m} / \mathrm{z}$ 378: (a) Llithium-cationized 1 at $\mathrm{m} / \mathrm{z} 464$; (b) the ion at $m / z 422$; (c) the ion at $m / z 378$.

cationized 1 and lithium-cationized 2 were demonstrated clearly by multi-stage IRMPD, and the multistage IRMPD spectra of lithium-cationized 1 and lithium-cationized 2 are shown in Figures 8 and 9, respectively. The proposed fragmentation genealogical relationship patterns for the lithium-cationized species are shown in Scheme $\mathbf{1 1}$.

\section{Rearrangement of Lithium-Cationized 5 and 6 in IRMPD}

The IRMPD spectrum of lithium-cationized 5 and 6 contains only the ion at $\mathrm{m} / \mathrm{z} 317$. The proposed forma-

tion pathway of the ion at $\mathrm{m} / \mathrm{z} 317$ is that the lithiumcationized 5 (or 6 ) first rearranges to lithium-cationized 9 (or 10) and then dissociates into the ion at $\mathrm{m} / \mathrm{z} 317$. This mechanism is similar to that of protonated 5 and 6 . However, there are two different points: (1) the multisite coordination effect of lithium ion may produce lithium-containing chelate bond connecting pyridine amine and pyrimidine amine, which plays an important role in the rearrangement and can be used to explain why this pathway is the exclusive dissociation pathway of lithium-cationized 5 (or 6 ). The proposed mechanism for the $S_{N} A r$ type rearrangements from lithium-cationized 5 (or 6) is shown in Scheme 12; (2) the formation of
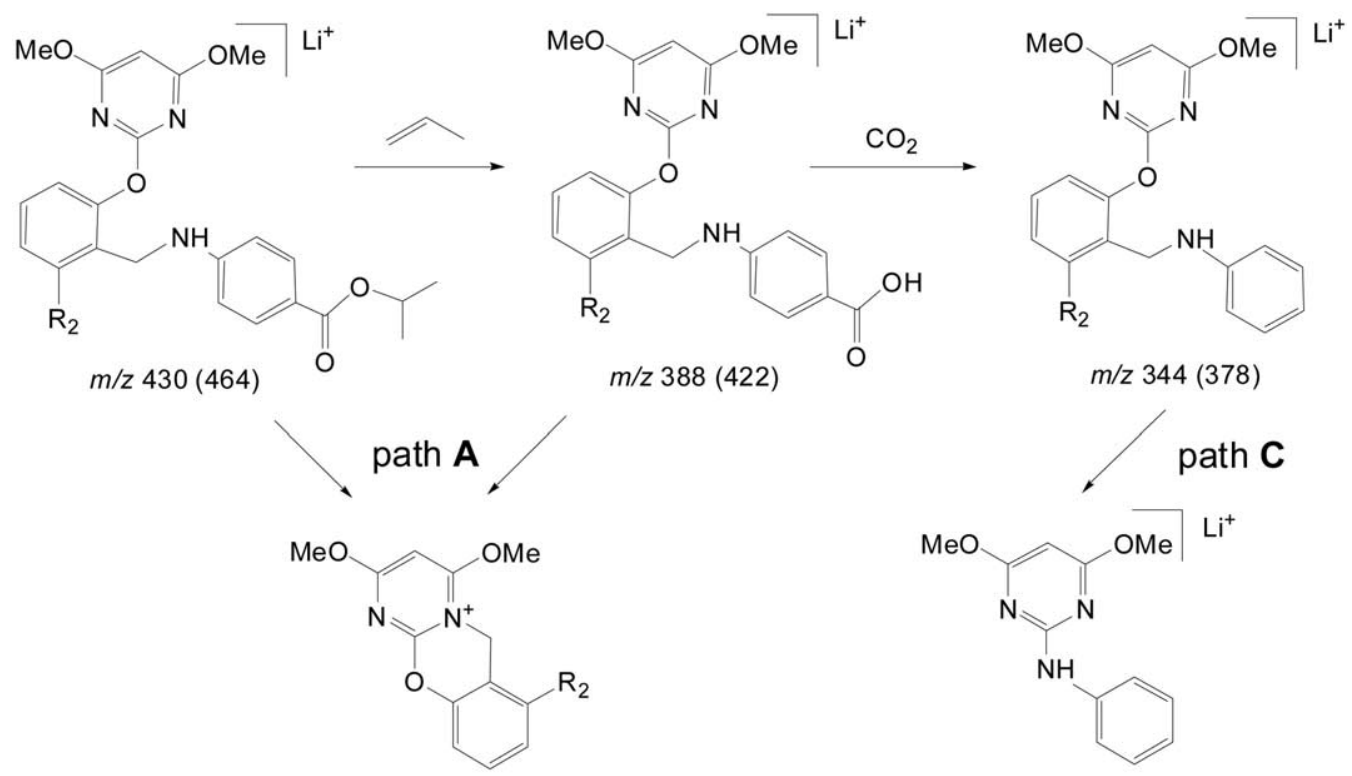

$K$ ion $m / z 245(279)$

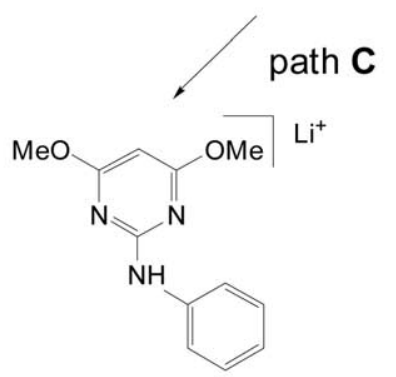

$F$ ion $m / z 238$

Scheme 11. Formation pathways of the product ion at $\mathrm{m} / \mathrm{z} 388$ (or 422), 344 (or 378), 245 (or 279), and 238 from IRMPD of lithium-cationed 1 (or 2). The data in parentheses are those observed, when $R_{2}$ is $\mathrm{Cl}$ substitute group. 

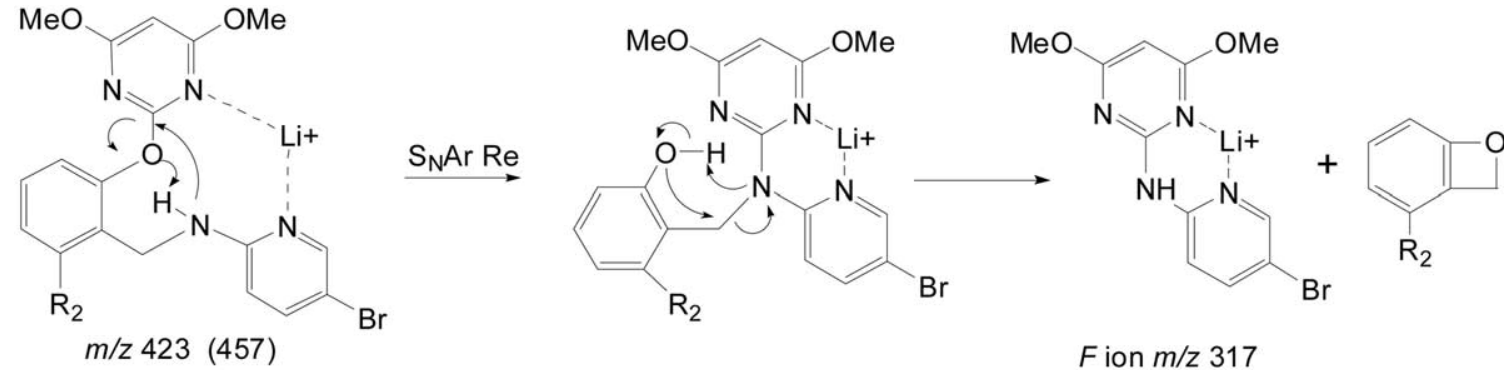

$F$ ion $\mathrm{m} / \mathrm{z} 317$

Scheme 12. Formation pathway of $F$ ions at $m / z 317$ from IRMPD of lithium-cationed 5 (or 6 ). The data in parentheses are those observed, when $\mathrm{R}_{2}$ is $\mathrm{Cl}$ substitute group.

the ion at $m / z 317$ from lithium-cationized 9 (or 10) may not involve an ion-neutral complex process. It is proposed that $\mathrm{H}$ rearranges from the form phenol hydroxyl to phenyl amine first and then the oxygen attacks the benzylic carbon, which induces the cleavage of the $\mathrm{C}-\mathrm{N}$ bond connecting the benzylic carbon and phenyl amine to form the ion at $\mathrm{m} / \mathrm{z} 317$.

\section{Conclusions}

This study demonstrates that the protonated and lithium-cationized compounds ( 1 to 8 ) undergo complicated rearrangements and fragmentations under IRMPD in a FT-ICR cell. It has been shown that the gas-phase intramolecular $S_{N} 2$ reactions play an important role in the formation of the $K$ ion series; an adjacent functional group capable of accepting $\mathrm{H}$ provides an alternative gas-phase $S_{N} A r$ type skeletal rearrangement pathway to form $F$ ion series. Based on comparison of IRMPD spectra and the in-source CAD spectra, the gas-phase rearrangement of protonated 5 and 6 was elucidated and highlighted. It is proposed that the formation of the $F$ ion at $m / z 311$ from protonated 9 (or 10) proceeds by way of ion-neutral complexes. Moreover, a gas-phase Cope type rearrangement mechanism is proposed to explain the formation of the $W$ ion series and is supported by the $\mathrm{H}-\mathrm{D}$ exchange experiment. Full understanding of the fragment pathway is important for the further metabolism and degradation research of these compounds. These rearrangement reactions may have significance for understanding gas-phase rearrangements of protonated species in general.

\section{Acknowledgments}

The authors gratefully acknowledge financial support by the National Natural Science Foundation of China (no. 20175034) and by the Chinese Academy of Sciences.

\section{References}

1. Chen, G. Q.; Guo, Y. L.; Cui, H.; Lu, L. Study on Two Characteristic Rearrangements and Degradation Patterns of Six Derivatives of 2-Pyrimidinoxal Aniline by $\mathrm{MS}^{\mathrm{n}}$ Technology. Ниахие Хиеbao 2001, 59, 1471-1475.

2. De Hoffmann, E. Tandem Mass Spectrometry: A Primer. J. Mass Spectrom. 1996, 31, 129-137.
3. De Hoffmann, E; Stroobant, V. Mass Spectrometry, 2nd ed.; John Wiley and Sons, Ltd.: Chichester, UK, 2001; pp 221-226.

4. Papayannopoulos, I. A. The Interpretation of Collision-Induced Dissociation Tandem Mass Spectra of Peptides. Mass Spectrom. Rev. 1995, 14, 49-73.

5. Reid, G. E.; Simpson, R. J.; O'Hair, R. A. J. A Mass Spectrometric and ab Initio Study of the Pathways for Dehydration of Simple Glycine and Cysteine-Containing Peptide $[\mathrm{M}+\mathrm{H}]^{+}$ Ions. J. Am. Soc. Mass Spectrom. 1998, 9, 945-956.

6. O'Hair, R. A. J.; Styles, M. L.; Reid, G. E. Role of the Sulfhydryl Group on the Gas Phase Fragmentation Reactions of Protonated Cysteine and Cysteine Containing Peptides. J. Am. Soc. Mass Spectrom. 1998, 9, 1275-1284.

7. Reid, G. E.; Simpson, R. J.; O'Hair, R. A. J. Leaving Group and Gas Phase Neighboring Group Effects in the Side Chain Losses from Protonated Serine and Its Derivatives. J. Am. Soc. Mass Spectrom. 2000, 11, 1047-1060.

8. Danieli, B.; Rubino, F. M.; Cremonesi, A. Fast Atom Bombardment Mass Spectrometry of Carbobenzyloxy-Protected Amino Acids and Peptides. Org. Mass Spectrom. 1989, 24, 225-229.

9. Mammoliti, E.; Sindona, G.; Uccella, N. Characterization of Z-Blocked Isomeric Dipeptides by Fast Atom Bombardment Tandem Mass Spectrometry and Kinetic Energy Release Measurements. Org. Mass Spectrom. 1992, 27, 495-501.

10. Qin, X. Z. Tandem Mass Spectrum of a Farnesyl Transferase Inhibitor Gas-Phase Rearrangements Involving Imidazole. J. Mass Spectrom. 2001, 36, 911-917.

11. Qin, X. Z. Tandem Mass Spectrum of a Growth Hormone Secretagogue: Amide Bond Cleavage and Resultant Gas-Phase Rearrangement. J. Am. Soc. Mass Spectrom. 2002, 13, 371-377.

12. Wang H. Y.; Guo Y. L.; Zhang, L.; An, D. K. Progress in Research on Gas-Phase $\mathrm{S}_{\mathrm{N}} 2$ Ion-Molecule Reaction by Mass Spectrometry. Youji Huaxue 2002, 22, 974-980.

13. Longevialle, P. Ion-Neutral Complexes in the Unimolecular Reactivity of Organic Cations in the Gas Phase. Mass Spectom. Rev. 1992, 11, 157-192.

14. Little, D. P.; Speir, J. P.; Senko, M. W.; O'Connor, P.B.; McLafferty, F. W. Infrared Multiphoton Dissociation of Large Multiply Charged Ions for Biomolecule Sequencing. Anal. Chem. 1994, 66, 2809-2815.

15. Little, D. P.; McLafferty, F. W. Sequencing 50-Mer DNAs Using Electrospray Tandem Mass Spectrometry and Complementary Fragmentation Methods. J. Am. Chem. Soc. 1995, 117, 6783-6784.

16. Colorado, A.; Shen, J. X.; Brodbelt, J. S. Use of Infrared Multiphoton Photodissociation with SWIFT for Electrospray Ionization and Laser Desorption Applications in a Quadrupole Ion Trap Mass Spectrometer. Anal. Chem. 1996, 68, 4033-4043.

17. Goolsby, B. J.; Brodbelt, J. S. Characterization of B-Lactams by Photodissociation and Collision-Activated Dissociation in a Quadrupole Ion Trap. J. Mass Spectrom. 1998, 33, 705-712. 
18. Goolsby, B. J.; Brodbelt, J. S. Tandem Infrared Multiphoton Dissociation and Collisionally Activated Dissociation Techniques in a Quadrupole Ion Trap. Anal. Chem. 2001, 73, $1270-1276$.

19. Crowe, M. C.; Brodbelt, J. S.; Goolsby, B. J.; Hergenrother, P. Characterization of Erythromycin Analogs by Collisional Activated Dissociation and Infrared Multiphoton Dissociation in a Quadrupole Ion Trap. J. Am. Soc. Mass Spectrom. 2002, 13, 630-649.

20. Solomons, T. W. G.; Fryhle, C. B. Organic Chemistry, 7th ed.; John Wiley and Sons, Ltd.: New York, USA, 1998; pp 10331034.

21. Luedersdorf, R.; Praejcke, K.; Schwarz, H. Stereochemistry Controlled Cope-Type Disintegration Process of Sulfinyl Compounds in the Mass Spectrometer. Org. Mass Spectrom. 1978, 13, 179-180.

22. Wolkoff, P.; Holmes, J. L. Cope and 1,3-Allylic Rearrangements and Ring Closure of the 1,5-Hexadiene Radical Cation
Prior to Decomposition in the Gas Phase. J. Org. Chem. 1982, 47, 3342-3344.

23. Rozeboom, M. D.; Kiplinger, J. P.; Bartmess, J. E. The Anionic Oxy-Cope Rearrangement: Structural Effects in the Gas Phase and in Solution. J. Am. Chem. Soc. 1984, 106, 1025-1029.

24. Lee, J. K.; Grabowski, J. J. Anion Structure Determination in the Gas Phase: Chemical Reactivity as a Probe. J. Org. Chem. 1996, 61, 9422-9429.

25. Schulze, S. M.; Santella, N.; Grabowski, J. J.; Lee, J. K. The Anionic Oxy-Cope Rearrangement: Using Chemical Reactivity to Reveal the Facile Isomerization of the Parent Substrates in the Gas Phase. J. Org. Chem. 2001, 66, 7247-7253.

26. Hsu, F. F.; Turk, J.; Stewart, M. E.; Downing, D. T. Structural Studies on Ceramides as Lithiated Adducts by Low Energy Collisional-Activated Dissociation Tandem Mass Spectrometry with Electrospray Ionization. J. Am. Soc. Mass Spectrom. 2002, 13, 680-695. 